\title{
Pregnancy in a severely mentally handicapped adult
}

\author{
Jean O'Hara St Bartholomew's Hospital, London
}

\section{Editor's note: At the coalface}

At the coalface is an intermittent series in which readers relate an ethical dilemma they have experienced themselves in the course of their work, with as much or as little analysis as they wish. The journal is keen to publish such reports and any reader wishing to contribute should send his or her paper (500-3500 words) to the Editor, Journal of Medical Ethics, clo Imperial College of Science, Technology and Medicine, 14 Prince's Gardens, London SW7 INA. Contributions can be published anonymously if the writer wishes.

\section{Author's abstract}

What happens when we discover that a severely mentally handicapped girl, resident under our care, is heavily pregnant? What options are open to us in her management? What are the legal and ethical issues involved? How do we ensure that she receives the best possible care and protection and will the involvement of the police actually make the situation worse? Few of us have had the experience of working through such dilemmas, and little help can be found in consulting 'experts' who are awaiting the result of 'test cases' in the High Courts. This article highlights some of the problems we encountered with such a case.

\section{Introduction}

During one normal working day at a large residential hospital for the mentally handicapped, I was asked to assess a 24-year-old, non-verbal female resident, who was refusing to let direct-care staff bathe her, or change her, and who was displaying an exacerbated level of hair-pulling (trichotillomania). This was thought to be secondary to her grandfather's failure to visit her over the last month due to a heart attack and his subsequent hospitalisation.

The resident entered the room in her usual fashion, she was slightly overweight and almost completely bald. To the nurse's surprise it did not take much persuasion to get her to comply, to a limited extent, with my examination. She lay on the bed with her legs

\section{Key words}

Mental handicap; pregnancy in mental handicap. apart, and allowed me to examine visually her genitalia, then she got up and left the room. I had noted a localised vulval irritation but nothing else, and concluded it was due to the recent difficulties with personal hygiene and her need to wear incontinence pads - for she remained doubly incontinent. Whilst I was still in the nurses' station she entered the room again, this time pointing to her lower abdomen and indicating she was in pain. She stood beside me as I laid my hand on her abdomen and felt a vague mass rising up to her umbilicus. Although it seemed most unlikely, it was then that I requested a pregnancy test - and this was followed by an ultrasound scan a weel later. It was confirmed she was 24-weeks pregnant.

This diagnosis posed considerable dilemmas fo both staff and relatives: no one seemed to know how best to handle the situation, and whilst we telephoned various agencies for advice - including the Health Authority's solicitors, the British Medical Association's Ethics Committee, the Medical Defence Union etc the moral-ethical-legal situation was far from clear, and we were informed of the results of various abortion/sterilisation cases of mentally handicapped individuals which had gone through the High Courts.

\section{The issues involved}

It seemed to us there were a number of issues involved.

a) What to do about the pregnancy itself?

b) The need to establish detailed psychometric assessment. If she was indeed severely mentally handicapped (ie IQ $<49$ ) then legally she would be considered incapable of giving consent, and therefore her pregnancy was the result of a criminal act.

c) Why had the pregnancy been undiagnosed until this late stage and what was the risk that such an incident should have occurred?

d) The emotional and practical support which would be needed whatever course the pregnancy was to take.

e) Future protection and contraception issues.

f) The impact on other residents in the same house.

g) Support for the family.

h) The need to support staff involved in the decisionmaking process and those in direct care.

I believe the multidisciplinary team involved went 
through a long period of soul-seaching and stress, trying to weigh up the various issues involved, whilst maintaining a professional, caring and responsible attitude. Such decisions were also prejudiced by our own personal biases and beliefs, and for a resident who could not speak for herself, any decision that was made would have to be the result of much multidisciplinary discussion. The procedures we undertook over the next few months are worth sharing with other professionals who may find themselves in a similar predicament in the future.

\section{What to do about the pregnancy?}

Our discussions focussed on the circumstances of the conception. The resident involved was a 'loner', who rejected the approach of others, especially men. She was not known to have a sexual relationship, was doubly incontinent, and 'protected' by large incontinence pads. We concluded that the pregnancy was the result of a sexual act which had been imposed upon her. Would any woman want to carry the result of such an abuse to term or would she not want to get rid of it as quickly as possible? Being the result of a criminal act, it was our duty as her professional carers to minimise any further distress. Our loyalty was primarily towards her, and not to the unborn fetus, though this view was challenged. However, the fetus was already 24 weeks by scan, fast approaching the legal limit for an abortion. If we were to recommend a termination it would have to be performed as a matter of urgency. We considered the chances of the fetus being either mentally or physically handicapped and the strong possibility of a recessive condition as there was the question of consanguinity. The scan and routine antenatal blood tests were all normal.

We discussed how the pregnancy had so far affected the resident. She was more difficult when it came to bathing, did not like her carers touching her, and was pulling out her hair in distress. Was this behaviour due to the abuse she had been subjected to, the recent hospitalisation of her grandfather or to the pregnancy? Or was it a combination of all three? Whatever decision was made she would undoubtedly suffer physical and emotional distress. Were she to continue to term, she would need support and counselling to prepare her during the antenatal period, close liaison with the obstetric team, a safe and private environment, and to be allowed to prepare and grieve for the loss of her newborn through immediate adoption. Were she to have a termination of pregnancy, it would have to be carried out legally and quickly and she would still need to be counselled and supported throughout.

Meeting with her relatives resulted in more unanswered questions, but basically they wanted to be advised by the medical staff involved in her care.

Eventually, after much consultation, the decision was a fait accompli, in the sense that the health authority were unable to find an obstetrician and midwife team who were willing to carry out a termination at this late stage and under such difficult circumstances. There were a few consultants who would do so, but clearly in the face of much opposition from their midwifery colleagues. Our legal advisers were also extremely uneasy with the whole situation and were unable to give us clear guidelines upon which to base our recommendation.

\section{Psychometric assessment}

There was no previous assessment on file and this was performed as a matter of urgency, basically to support any recommendation we would make should the case come before the courts. On the non-verbal Coloured Progressive Matrices test, she scored an equivalent IQ of below 40 , putting her legally in the severely mentally handicapped range.

In her summary, the clinical psychologist concluded that she was very dependent on direct-care staff in all areas of self care. 'She is neither literate nor numerate and her speech is limited to one or two words. She is able to name many pictured and concrete objects via the use of Makaton signing and is able to identify parts of her body.' She understood instructions containing prepositions for example 'on', 'in', 'behind'.

\section{Protection issues and police involvement}

This resident was never considered to be 'at risk' of a pregnancy, and the question of contraception did not arise in any of her regular review meetings. It was discussed once, with her next of kin, when 'bruises were noted on the inferior aspects of both her breasts but these were clinically hyperaemic (reddened) patches, attributed to her persistent habit of resting her breasts on radiators as she looked out of the window.

She had never returned to her house in any distressed state or suspicious circumstance and spent much of her time away from the hospital with her grandparents. In view of her history, it was most likely that the perpetrator was someone she knew very well. Male staff, residents and relatives were under suspicion.

The Police Child Protection Team visited the hospital, and much to everyone's relief they were tactful, responsive, caring, careful and very professional. With the support of nursing and psychology staff, they were able to interview our resident on two separate occasions, using anatomically correct dolls. On both occasions she made the same disclosure, in spite of much distress, and the police are now pursuing their own investigations. From these interviews we learned that she had been the victim of sexual abuse for many years.

The question of further contact with her family was discussed. On the one hand she seemed happy and benefited greatly from these visits, but on the other we also had to protect her from any further incident. The family were allowed to visit, in the open areas of the hospital only, and always in the presence of a member of staff.

\section{The antenatal period}

Over the next few months a core group from the 
hospital, adult training centre and social services department met on a regular basis, to discuss various practical issues of management, and to offer support to those counsellors actually working with the resident.

In order to afford her the necessary privacy of her own environment, a partitioned room was built for her in the house (after consultation with the local fire officer). This room was painted, decorated and comfortably furnished. We resisted the less expensive option of transferring her to another house in the hospital grounds, as we did not want her to feel isolated, abandoned or punished.

\section{Emotional and social support}

We discussed the need for us all to use the same, simple basic language. Initially we made slow progress, unsure whether or not she was able to grasp the idea of a baby inside her. We used pictures and photographs, avoiding childish dolls which we thought inappropriate, and anatomically correct dolls because they had been used in the disclosure interviews. We stressed that her job was to look after the baby whilst it was still inside her, by keeping healthy and well rested. We also introduced, in a positive manner, the need for adoption afterwards, saying the baby was going to a 'Mummy and Daddy' to be looked after whilst we continued to look after her in much the same way. Over the next few weeks we were unsure if she was grasping such difficult concepts, but gradually she seemed to understand more and more, showing initial ambivalence to the loss of her future child and later actually crying. This degree of understanding was quite remarkable, and encouraged us to continue with our intense level of emotional support. To aid the bereavement process we produced a storyboard of her own pregnancy, adding to it photographs at different stages, and completing it with the birth and the adoption.

As far as her hair-pulling behaviour was concerned, it was hoped that an increased awareness would result in the lessening of such destructive activity, reinforced by social praise, compliments, wearing new, bright maternity clothes she had helped to choose, and the use of make-up and perfume. At this stage we also introduced a music therapist as another means of exploring and understanding her emotions.

\section{Practical problems}

Apart from anxieties from transport staff about her continued attendance at the adult training centre, she attended right up until her 34th week of gestation, and afterwards her base workers maintained contact via regular visits to the hospital.

Our liaison with the local obstetric team at the nearby district general hospital at times proved to be a stressful one. Our own nursing staff had no general medical or obstetric training and were obviously anxious about their own coping skills. More importantly, with the resident's incontinence and lack of communication, they felt unsure about recognising the signs and symptoms of labour.
We also tried to encourage an early decision about the mode of delivery envisaged, taking into account her severe learning difficulties. However, the strong commitment to 'normalisation' so often stressed by those working within the discipline, demanded that such a decision be made purely on medical grounds at 38 weeks, after radiological pelvimetry. We were thus unable to prepare our resident for the possibility of a Caesarean section.

The principle of normalisation also meant that there were many advocates speaking on our resident's behalf, demanding alternative methods of pain control and labour, including the use of a birthing pool. It was important at this stage that we did not allow our own strong biases and experiences to be imposed upon a severely mentally handicapped woman.

Finally, in the event of a Caesarean section, the social services department at the district general hospital met with our resident's next of kin, and got them to sign the required consent form for such an operation. Then, in an effort to be helpful to all concerned, they also got a consent form signed for a sterilisation procedure at the same time! It was only by the continued good communication between staff and relatives that we discovered this in time to rectify the situation.

\section{Epilogue}

The resident was safely delivered of an $8 \mathrm{lb}$, healthy and normal female infant by elective Caesarean section at 38 weeks. The obstetric team involved showed tremendous compassion and skill in caring for her throughout her confinement, and were even at the entrance to greet her when she arrived. The baby went to foster parents two days after birth, but thankfully it was done properly, with time for our resident to say 'goodbye', to hand her child over to the new mother, and for photographs to be taken. What remains now is her continued counselling and emotional support as well as the issue of her safety and protection.

There are no clear rights or wrongs in dealing with such a complex situation. During the months preceding the birth there were numerous hurdles to overcome, causing us to question our own morals, stretching our skills and therapeutic techniques, and testing the practicalities of working in a truly multidisciplinary setting which involved liaison between departments, hospitals, and health and local authorities. The anxieties engendered in us all had to be recognised and supported. Whilst I have not even begun to address, in this article, the other concerns we faced, or the support offered to the family, fellow residents and students etc I believe we all contributed to the resident's high quality of care, and we have all learnt something from this shared experience.

Dr Fean O'Hara MBBS MRCPsych is Senior Registrar in Mental Handicap, Department of Psychological Medicine, St Bartholomew's Hospital, London ECIA $7 B E$. 